\title{
BERTAHAN MELALUI PERBUDAKAN: Sejarah Alternatif Tanah Merah
}

\author{
Surviving Through Slavery: \\ The Alternative History of Tanah Merah
}

\author{
Taufik Ahmad \\ Balai Pelestarian Nilai Budaya (BPNB-Makassar) \\ Jl.Sultan Alauddin Makassar \\ Email: taufik_mukarrama@yahoo.com
}

Naskah diterima tanggal 2 Januari 2013. Naskah direvisi tanggal 23 Januari 2013. Naskah disetujui tanggal 15 Pebruari 2013

\begin{abstract}
Abstrak
Pergeseran politik dari rezim orde baru ke era reformasi pada dasarnya telah memberi ruang gerak lebih luas kepada ilmuwan sosial terutama sejarawan untuk melakukan berbagai penelitian, termasuk tema penelitian yang secara politik sensitif pada masa orde baru. Sejarah tahanan politik yang dilihat dari berbagai perspektif di berbagai daerah mulai mendapat perhatian dan pelan-pelan menjadi alternatif dari sejarah orde baru cendrung militeristik. Sejarah dari mereka yang tidak memiliki sejarah (people without history) pada masa orde baru telah mendapat ruang di era reformasi. Tukisan ini mencoba menganalisis sejarah alternatif Tanah Merah (Mongcongloe, Sulawesi Selatan). Melalui pengalaman sehari-hari (daily experiences) masyarakat tahanan politik dalam kamp pengasingan yang mencoba bertahan hidup di bawah perbudakan militer, artikel ini menangkap trayektori sejarah dari proses dialektika antara kontrol militer orde baru di kamp tahanan Tanah Merah dengan respon yang diberikan oleh masyarakat tahanan politik selama 1965-1978. Ada interelasi hubungan yang dinamis, berfluktiatif, saling memberi pengaruh dari satu periode ke periode lainnya antara kontrol militer dengan respon masyarakat tahanan politik.
\end{abstract}

Kata kunci: strategi bertahan, tahanan politik, control dan respon

\begin{abstract}
Political shift from New Order regime to the Reformation Era has basically given wider space for social scientists, particularly historians to conduct various researches, including political topics which are politically sensitive in the New Order regime period. Regarded from various perspectives, the history of political prisoners has now begun to get attention in many places, and slowly become the alternative of New Order regime which was turned to be militaristic. The history of those who were without history in New Order regime has been acceptable and got sufficient space in reformation era. This article attempts to analyze the alternative history of Tanah Merah (Moncongloe, South Sulawesi) through daily life experience of the political prisoners in exile camp who were trying to survive under the military slavery. The article also tries to capture the historical trajectory of dialectical process between the New Order military control in The Tanah Merah detention camp and the responses given by the military prisoners during 1965-1978. There is a dynamic, fluctuated, and influencing interrelated relationship between the military control and the response of prisoners' community from one period to another period.
\end{abstract}

Keywords: survival strategy, political prisoners, control and response

\section{PENDAHULUAN}

$\mathrm{T}$ Tanah Merah adalah nama lain untuk menyebut Moncongloe, sebuah daerah yang berada di perbatasan Kabupaten Gowa dan Maros, dan sekitar 30 meter dari Kota Makassar. Sebelumnya, daerah ini merupakan hutan yang cukup lebat kemudian berubah menjadi kamp pengsingan Tahanan politik PKI. Istilah Tanah Merah itu sendiri baru muncul sekitar tahun 1970an. Ditinjau dari sudut historis, informasi tentang Moncongloe tergolong masih minim. Dalam literatur sejarah cenderung hanya menyebut nama Moncongloe sebagai suatu wilayah administratif 
tanpa penjelasan keberadaan masa lalunya. Nama Moncongloe dalam sejarah Gowa Tallo ditemukan dengan nama Gallarang Moncongloe. Pada saat kerajaan Tallo menjadi kerajaan otonom, daerah ini dikuasai oleh Karang Loe ri Sero bersama beberapa Gallarang lainnya (Razak, T.th: 8 dan Mattulada, 1982). Pada masa pemerintahan Belanda daerah Moncongloe berada di wilayah administratif Onderafdeling Maros. Kemudian, setelah bangsa Indonesia mencapai kemerdekaannya, daerah sekitar Moncongloe dijadikan Home Base Kodam XIV Hasanuddin. Pada tahun 1984 Moncongloe kemudian diserahkan kepada pemerintah daerah Maros dan Gowa sebagai wilayah administratif. Moncongloe kemudian dibagi menjadi dua, sebelah utara menjadi wilayah Kabupaten Maros dan sebelah selatan menjadi wilayah Kabupaten Gowa.

Lalu, mengapa Tanah Merah melekat untuk menyebut Moncongloe? Paling tidak terdapat tiga sebab, pertama, struktur tanah Moncongloe yang berbukit-bukit memiliki jenis tanah merah, kedua, daerah ini telah dikenal sebagai rawan kekerasan perampokan. Dalam sejarah gerakan bandit di Sulawesi Selatan, wilayah hutan yang membentang antara Moncongloe sampai Polongbanngkeng seringkali disebut sebagai salah satu tempat persembunyian perampok sejak periode kolonial sampai era 1960-an (Ahmad, 2013). Ketiga, Moncongloe merupakan daerah tempat pengasingan tahanan politik PKI (1969-1978). Orang-orang PKI yang seringkali dilabelkan dengan orangorang merah adalah bukan tidak mungkin menjadi penyebab semakin melekatnya nama tanah merah untuk menyebut Moncongloe. Terlepas dari persepsi tentang Moncongloe dan apakah itu direkonstruksi untuk memberi label negatif kepada Tahanan Politik PKI atau karena merupakan daerah rawan kekerasan dan perampokan, daerah ini merupakan salah satu wilayah yang cukup terisolasi dari segi informasi dan geografis serta senyap dari debatdebat sejarah pada periode Orde Baru. Tentang Moncongloe sebagai tempat pengasingan Tahanan politik PKI nyaris tidak ditemukan informasi dalam berbagai literatur.

Nampaknya negara Orde Baru, seperti dikatakan James Scott (1998), cenderung menyederhanakan realits sosial masa lalu yang kompleks ke dalam struktur-struktur dan klaisifikasi yang dapat digunakan negera untuk mengendalikan masyarakatnya. Akibatnya, terjadi proses "pemiskinan" pengetahuan sejarah Orde Baru telah menghilangkan keberagaman sejarah yang sebetulnya berfungsi menyanggah "kebenaran tunggal" alat elit yang memerintah. Dengan kata lain, proses demokratisasi dalam penulisan sejarah dan penafsiran sejarah dan proses otonomisasi sejarawan masa masa ini semakin mengecil kalau bukan dikatakan hilang sama sekali. Setelah negara Orde Baru berakhir, masyarakat mulai mempertanyakan kebenaran sejarah dan studi sejarah alternatif pun mulai mendapat tempat dalam historigrafis Indonesia. Sejarah pun dilihat dalam konteks yang lebih luas dan kritis (Nordholt, 2008). Sekaitan dengan itu, studi ini berupaya membalikkan klaim sejarah Orde Baru dari sejarah people without history menjadi people with their own history, sejarah orang-orang yang berada dalam pengasingan, orang-orang yang kalah dalam pergantian rezim, dan sejarah orang yang dianggap sesat secara ideologi oleh negara Orde Baru.

Fokus perhatian dalam tulisan ini adalah Tahanan politik PKI sebagai orang-orang yang mendapat pelabelan sosial yang selalu digolongkan sebagai masyarakat tidak bersih lingkungan dengan berbagai stempel buruk yang dikenakan kepada mereka. Tetapi pada saat yang sama, para petugas militer di dalam kamp pengasingan juga mengandalkan sumber tenaga dan pikiran para tahanan politik untuk kepentingan pribadi dan institusi militer. Tahanan politik diarahkan untuk membuka lahan perkebunan dan membangun infrastruktur untuk kepentingan militer. Hal ini membuka ruang kontrol dan eksploitasi tenaga tahanan politik secara besar-besaran, sehingga dapat dikatakan bahwa militer satu-satunya unsur yang paling diuntungkan atas pembukaan kamp pengasingan di Moncongloe (Ahmad, 2009).

Artikel ini ingin melihat pengalaman sejarah tahanan politik selama masa pengasingan di mana kontrol militer dan strategi bertahan tahanan politik berjalan beriring dan berdinamika. Periode pengasingan menyimpan sejumlah kisah seharihari mereka sebagai tahanan memperlihatkan perjuangan tidak kalah sulitnya sebagai kelompok social yang distigma buruk oleh Negara. Melihat fokus pada tahanan politik, memungkinkan kita mempelajari bagaimana mentalitas itu memberi peranan dalam menentukan pola politik yang selalu berubah sepanjang dalam pengasingan. Dalam hal ini saya ingin melihat bagaimanakah politik seharihari mereka selama dalam kamp pengasingan pada saat yang sama kontrol militer berjalan begitu kuat.

Jika politik di sini dimaksudkan dalam arti siapa yang mendapatkan apa dan bagaimana mendapatkannya (who gets what and how), maka dalam pengertian ini, politik tahanan politik tidak hanya berurusan dengan aksi-aksi politis yang tergabung dalam komunitas tahanan politik, tetapi politik mereka sehari-hari untuk memenuhi kebutuhan hidup dan/atau strategi bertahan selama 
dalam pengasingan, seperti tempat tidur, makanan, air, menghindari kekerasan petugas, menghindari korve, mencari penghasilan tambahan, mencuri hasil kebun petugas, dan lain sebagainya. Sebagai sebuah komunitas yang diikat dengan ikatan ideologis dan etnik, saya akan melihat bagaimana bentuk solidaritas dan politik sehari-hari mereka terhadap berbagai tekanan yang datang dari kontrol militer. Yang tersaji kemudian sebuah penggambaran trayektori dan dinamika yang fluaktuatif antara control militer dengan respon Tahanan politik.

\section{PEMBAHASAN \\ Kontrol Militer dan Respon Tahanan Politik Dalam Penjara}

Dalam upaya memperkuat hegemoninya, pemerintah Orde Baru melakukan kontrol yang ketak terhadap orang-orang yang dianggap komunis. Mereka harus disterilkan dan diisolasi dari masyarakat. Sulawesi Selatan sebagai salah satu basis PKI yang cukup berkembang pada tahun 1960an tidak luput dari perhatian pemerintah. Orang-orang yang dianggap komunis atau memiliki hubungan dengan PKI di daerah ini ditangkap dan diasingkan serta mendapat kontrol negara yang kuat melalui militer. Kontrol militer menyangkut mengendalikan tahanan politik PKI melalui berbagai instrumen yang bertujuan untuk memperkuat hegemoni. Kontrol militer terlihat sejak periode penangkapan dan pemenjaraan. Secara fisik kontrol dilakukan dengan menerapkan aturan-aturan ketat terhadap tahanan politik. Kontrol dalam penjara bermula Oktober 1965 sampai Maret 1966 dimana jumlah tanahan politik meningkat dengan cepat hingga mencapi 9.765 orang untuk wilayah Sulawesi Selatan dan Tenggara.(Ahmad, 2009: 123). Mereka berasal dari latar belakang etnik berbeda-beda, di tempatkan di penjara-penjara yang tersebar di Sulawesi Selatan danTenggara. Etnik Thionghoa, Bugis-Makassar dan Melayu memperlihatkan politik sehari-hari yang berbeda selama dalam penjara dan kamp pengasingan.

Pada awal penahanan, para tahanan politik hanya mendapat jatah makanan yang minim, dan aturan besuk diberlakukan sangat disiplin, yaitu sekitar pukul 13.00 siang hari dalam waktu yang singkat (Kadullah, tt). Awal tahun 1966, jatah makanan dihentikan. Para tahanan hanya berharap bantuan dari keluarga yang membesuk (Wawancara Kadullah, 26/8/2008). Jadwal besuk diperbolehkan setiap hari Kamis dan dibatasi hanya 30 orang pembesuk. Kebijakan ini merugikan para tahanan politik, karena sebagian besar kebutuhan pangan bertumpu pada keluarga mereka. Makanan yang diperoleh di Penjara tidak mencukupi kebutuhan fisik para tahanan politik. Di samping itu, pembesuk semakin berkurang dari hari ke hari karena semakin merosotnya keadaan ekonomi keluarga tahanan politik. Keluarga tahanan politik sebagian sudah tidak memiliki asset karena rumah-rumah mereka sebagian telah dimusnahkan oleh massa atau diambil alih oleh pemerintah orde baru dan keluarga tahanan politik dikucilkan di lingkungan masyarakat sehingga akses ekonomi mereka tertutup.

Di tengah kondisi yang buruk, tahanan politik berusaha bertahan hidup dengan melakukan berbagai pola. Diantaranya memelihara ikan di kolam-kolam kecil, berkebun di depan penjara, dan memanfaatkan saluran air kemudian disaring untuk keperluan air minum pada musim kemarau. Ei Ken Heng, seorang tahanan politik yang memiliki keahlian dalam bidang farmasi menjadi tumpuan bagi tahanan politik. Setiap makanan dan minuman yang diusahakan sendiri tahanan politik, seperti ikan saluran air, kodok, dan tumbuh-tumbuhan diperiksa terlebih dahulu untuk melihat aman atau tidaknya untuk dikonsumsi (Wawancara Anwar Abbas di Makassar, 20/6/2008). Ei Ken Heng memotivasi tahanan politik untuk berinisiatif untuk menanam sayur-sayuran dan buah-buahan di depan penjara. Sayuran yang telah ditanam tersebut setidaknya dapat membantu mengurangi kekurangan gizi para tahanan (Wawancara Cak Gun di Makassar, 20/7/2008) Jenis sayur yang ditaman seperti bayam dan buah tomat, cabai dan lain sebagainya. Sayur biasanya dicampur dengan kuah daging, tahanan politik hanya mengambil beberapa lembar dari sayur tersebut kemudian dicampur dengan kuah daging (Wawancara Anwar Abbas di Makassar, 20/6/2008). Selain menanam sayur, tahanan juga memanfaatkan segala daya mereka untuk mempertahankan hidup. Seperti pemeliharaan ikan-ikan kecil di saluran air (got) penjara kemudian dijadikan lauk pauk (Wawancara Kadullah, 26/8/2008).

Kondisi tahanan politik dalam penjara yang semakin hari semakin buruk sehingga muncul provokasi perlawanan terhadap petugas penjara. Resistensi Tahanan politik dengan koordinasi cukup rapi, mereka melakukan perlawanan secara tersembunyi dan penuh kehati-hatian, mencuri makanan di dapur atau menyembunyikan makanan, mengelabui petugas dengan berpura-pura sakit untuk menghindari kerja bakti, dan lain sebagainya. Upaya tahanan politik ini sama sekali tidak diketahui oleh petugas penjara. Dalam bentuk nyata mereka melakukan perlawanan dengan cara aksi mogok makan. Aksi ini dimaksudkan memprotes jatah makan yang tidak sesuai dengan standar kebutuhan manusia (Wawancara Anwar Abbas di Makassar, 
2/6/2008; Wawancara Sarmanto Sarmo di Makasar, 14/6/2008; Wawancara Cak Gun di Makassar, 16/6/2008). Boleh jadi perlawanan yang diberikan dengan cara mogok makan itu sebuah langkah tepat untuk menekan pihak penjara agar meningkatkan jatah makan mereka, atau sekaligus sebuah langkah frustasi sehingga memilih sekalian tidak makan daripada menerima jatah makan sangat sedikit.

Respon tahanan politik terhadap kontrol militer berujung pada upaya resistensi yang solid. Ini disadari oleh Teperda sebagai suatu yang harus diselesaikan. Bentuk kesadaran ini sehingga pihak Kodam XIV Hasanuddin mulai memikirkan langkah-langkah kongkrit agar para tahanan dapat bertahan dan tidak membutuhkan dana yang banyak. Banyaknya tahanan politik yang meninggal dan resistensi tahanan politik serta persediaan dana yang minim menjadi pertimbangan perlunya pemanfaatan tahanan politik di lokasi tertentu yang mudah dikontrol oleh militer. Pemikiran ini menjadi cikal bakal berdirinya Kamp Pengasingan tahanan politik Moncongloe. Hal ini juga berdasarkan kewenangan-kewenangan yang diberikan Pangkopkamtib kepada Kodam XIV Hasanuddin untuk menyelesaikan pengamanan dan pembinaan tahanan politik (Arsip Muhammad Saleh Lahade Reg. 441).

\section{Dalam Kamp Pengasingan}

Dalam pandangan yang lebih ekstrim, periode pengasingan tahanan politik dapat dikatakan sebagai periode perbudakan tahanan politik. Pada periode ini, tenaga tahanan politik dieksploitasi untuk kepentingan militer, seperti kerja paksa yang dibebankan kepada mereka, membuka lahan perkebunan untuk anggota militer, dan bekerja di rumah-rumah militer tanpa mendapat upah. Ada tiga pola eksploitasi tenaga kerja tahanan politik di Moncongloe: pertama, korve dan konsentrasi tahanan politik di Kamp Inrehab. Kedua, tahanan politik dikerahkan untuk bekerja pada proyek pembangunan unit kantor Kodim dan perumahan militer, serta ada juga yang membangun rumah pribadi anggota militer (Wawancara Cak Gun di Makassar, 20/7/2008). Ketiga, Tahanan politik bekerja di rumah-rumah anggota Kiwal Kodam XIV Hasanuddin. Ketiga pola eksploitasi ini dilakukan oleh militer kepada semua tahanan politik. Tidak ada perlakukan khusus yang diberikan petugas berdasarkan etnisitas dan/atau perbedaan daerah asal, tetapi terdapat pola berbeda dalam merespon kontrol militer. Perbedaan latar belakang sosial budaya tahanan politik mencerminkan pola dan strategi politik sehari-hari yang berbeda dalam menghadapi kontrol militer.
Kontrol yang berlapis dilakukan oleh militer terhadap tahanan politik, baik untuk kepentingan pribadi maupun institusi militer, dan kontrol itu digeneralisir pada semua level hubunganhubungan sosial tahanan politik melahirkan pola resistensi dan akomodasi tahanan politik sebagai strategi untuk bertahan hidup. Pada situasi tertentu tahanan politik melakukan resistensi terhadap kontrol dan pada lain waktu sikap akomodasi menjadi pilihan tepat. Motivasi dan tujuan politik resistensi dan akomodasi, secara personal pada diri tahanan politik juga menunjukkan keberagamanan background mereka. tahanan politik berasal dari latar belakang berbeda-beda sehingga menunjukkan ekspresi berbeda terhadap kontrol yang ditujukan kepadanya.

Pada respon paling kecil menghadapi kontrol adalah bermalas-malasan bekerja di kebun petugas. Prilaku resistensi ini, misalnya selalu dilakukan oleh Cak Gun yang mendapat tugas bekerja di kebun petugas yang paling jauh dari kamp Inrehab. Kebun yang sulit dijangkau dengan jalan kaki dimanfaatkan oleh Cak Gun untuk bermalas-malasan bekerja di kebun petugas (Wawancara Cak Gun di Makassar, 20/7/ 2008). Bentuk perlawanan semacam ini dilakukan secara personal. Akan tetapi kecenderung resistensi dengan sikap bermalas-malas hampir dialami oleh tahanan politik setiap ada kesempatan. Bentuk perlawanan ini tidak dimaksudkan untuk merubah sistem dominasi militer tetapi sebuah tindakan yang timbul akibat represif dari militer itu sendiri. Kejenuhan dan frustasi mewarnai pola-pola seperti ini.

Politik terhadap kontrol militer yang lain dengan melakukan pengrusakan kebun-kebun petugas secara sembunyi-sembunyi. Salah satu kasus yang dialami oleh Anwar Abbas, dalam proses pengerjaan kebun-kebun petugas yang dibebankan kepadanya secara sengaja memotong akar-akar singkong sehingga tidak menghasilkan apa-apa pada saat panen. Upaya resistensi ini sebagai bentuk penolakan tersembunyi terhadap korve yang dibebankan kepada tahanan politik (Wawancara Anwar Abbas diMakassar,20/12/2008). Pengrusakan kebun-kebun petugas dilakukan dengan keberanian dan kesiapan mental yang cukup baik, karena resiko resistensi ini sangat besar pula. tahanan politik yang melakukan resistensi dalam aksi merusak milik pribadi petugas biasanya dilakukan oleh anggota PKI yang memang telah terbentuk dalam dirinya sikap anti kemapanan. Namun, sikap protes tersebut tidak dapat disalurkan dalam bentuk frontal sehingga dilakukan secara sembunyi-sembunyi untuk merugikan petugas.

Kasus politik tahanan politik lain diperlihatkan oleh Anwar Abbas dengan melakukan pembunuhan 
binatang-binatang ternak milik petugas inrehab. Alasan pembunuhan ternakitu, bahwa apabila ternak terlalu banyak maka akan menyulitkan tahanan politik untuk memeliharanya. Anak-anak kambing milik petugas terpaksa dibunuh oleh Anwar Abbas pada saat dilahirkan agar dapat mengurangi beban tahanan politik. Modus perlawanan ini dilakukan bekerjasama dengan Dr. Untung dengan melakukan analisa-analisa kematian anak-anak kambing tersebut dengan argumentasi yang direkayasa. Penjelasan-penjelasan yang dibuat-buat oleh Dr. Untung dimaksudkan untuk menjaga keselamatan tahanan politik lain (Wawancara Anwar Abbas di Makassar, 20/12/2008).

Selain itu, pencurian buah labu dari kebun milik petugas kerap kali dilakukan untuk selanjutnya dibagi-bagikan kepada penduduk sekitar Moncongloe. Pencurian labu dilakukan utamanya di kebun-kebun petugas yang melakukan kontrol kuat terhadap tahanan politik. Modus pencurian ini dibagi atas berbagai orang yang melakukan pengintaian atau pengamatan terhadap petugas dengan mempelajari saat-saat kapan petugas tersebut menuju ke kota Makassar. Pada saat petugas tidak ada di tempat, tahanan politik mencuri labu kemudian sebagian diberikan kepada penduduk dan sebagian lagi diberikan kepada Tahanan politik lain (Wawancara Anwar Abbas di Makassar, 20/12/2008).

Politik resistensi membunuh ternak dan mencuri hasil kebun petugas dilakukan dengan aksi bersama. Beberapa tahanan politik melakukan aksi ini dengan berkordinasi dengan tahanan politik yang lain. Mereka merencanakan, mengamati keberadaan petugas kemudian melakukan aksi. Sebagian besar tahanan politik yang melakukan resistensi adalah mereka yang berasal dari anggotaanggota PKI dengan pengetahuan resistensi yang cukup baik.

Politik akomodasi nampaknya lebih diperlihatkan oleh sejumlah tahanan politik, terutama mereka yang berasal etnik Tionghoa. Politik akomodasi dapat dilihat dalam berbagai prilaku tahanan politik yang berusaha mendekati petugas inrehab secara personal dengan memberikan hasil-hasil hutan kepada petugas. Salah satu contoh, untuk melunakkan hati petugas, Go Kee Iet kerap kali memberikan minyak ular yang didapat di hutan. Tahanan politik etnik Thiongkoa lebih jeli melihat kebutuhan-kebutuhan atau kegemaran-kegemaran petugas untuk menghindari perlakukan keras dari petugas. Sikap akomodasi juga dilakukan dengan memberikan sanjungan atas kehebatan petugas (militer) dalam berbagai bidang. Politik akomodasi ini mendapat tempat yang cukup baik dalam kamp pengasingan karena kelebihan-kelebihan mereka dalam berbagai aspek. Misalnya pengetahuan mereka tentang obat-obatan herbal dengan mudah mendapat kepercayaan petugas. Demikian pula kelebihan mereka dalam bidang perdagangan sehingga Tahanan politik etnik Tionghoa mendapat tugas kerja untuk mengelolah koperasi tahanan politik. Unit Usaha Produksi Koperasi Tahanan politik Moncongloe ditangani oleh Go Kee Iet, seorang Tahanan politik etnik Tionghoa. Go Kee Iet bertugas menghitung jumlah produksi hutan masuk dan keluar, seperti bambu, kayu untuk tiang rumah, batu gunung dan lain sebagainya. Mengenai hasil penjualan bambu, kayu dan batu gunung diserahkan kepada petugas Inrehab (Wawancara Go Kee Iet di Makassar, 26/8/2008).

Koperasi menjadi tumpuan bagi tahanan politik untuk memperbaiki kehidupannya, kendatipun pada akhirnya koperasi ini berkembang di bawah kontrol petugas, bahkan menjadi sarana bagi petugas Inrehab untuk mengeksploitasi sumber daya tahanan politik. Dalam catatan Munir dikatakan bahwa:

"Sedikit saya bisa memberikan bayangan sebagai salah satu cara untuk meringankan saya ialah bahwa di sana (Moncongloe) kami ada mempunyai koperasi yang anggota-anggotanya terdiri dari tahanan politik semua dari pelaksananya (pengurusnya) dari tahanan politik juga tetapi akan pengawasan petugas (CPM).

Catatan ini memperlihatkan koperasi tahanan politik sebagai tumpuan harapan, namun tetap menjadi sarana eksploitasi tahanan politik. Menghadapi kondisi demikian, Go Kee Iet bekerjasama dengan tahanan politik lain terkadang menyelundupkan hasil-hasil hutan untuk dijual ke penduduk setempat, atau ditukar dengan kebutuhan sehari-hari (Wawancara Go Kee Iet di Makassar, 26/8/2008).

Respon lain diperlihatkan Tahanan politik dengan sikap disiplin terhadap pekerjaan yang diberikan kepada tahanan politik. Beberapa tahanan politik berdisiplin dalam kehidupan seharihari, baik dalam bekerja, beribadah, maupun pada saat upacara setiap hari senin. tahanan politik memperlihatkan sikap seperti ini pada dasarnya sebagai bentuk sindiran halus bahwa kepribadian Tahanan politik pada dasarnya tidak seperti yang dipersepsikan oleh pemerintah sebagai orang jahat dan kejam. tahanan politik juga ingin menunjukkan kekerdilan seorang petugas yang mengeksploitasi tenaga tahanan politik untuk kepentingan pribadi.

Politik sehari-hari tahanan politik di atas memperlihatkan pola yang berbeda antar tahanan politik itu sendiri. Nampaknya faktor etnisitas, budaya dan latar belakang tahanan politik memberi 
ruang perbedaan respon terhadap kontrol. Etnik Tionghoa lebih memiliki politik akomodasi dengan petugas dengan memanfaatkan keahlian mereka, sedangkan politik tahanan politik etnik Melayu lebih memperlihatkan resistensi terhadap kontrol militer. Kendatipun demikian, antara tahanan politik etnik Tionghoa dan tahanan politik etnik Melayu selalu bekerjasama pada aspek tertentu, seperti tahanan politik etnik Tionghoa tetap membantu tahanan politik lain dalam menjual hasil-hasil hutan secara gelap ke penduduk setempat, serta memberi ruang komunikasi yang baik di antara tahanan politik.

\section{PENUTUP}

Dari uraian di atas tampak bahwa kontrol dan politik sehari-hari tahanan politik senantiasa berubah, berdinamika seiring dengan perubahanperubahan kontrol militer. Respon tahanan politik juga memperlihatkan pola yang beragam. Di dalam kamp pengasingan Moncongloe tampak bahwa terdapat politik sehari-hari tahanan politik lebih bersifat akomodatif terhadap petugas militer. Akomodatif tahanan politik lebih diperlihatkan dalam bentuk pemberian makanan dan obat-obatan kepada petugas militer. Kemudian perlawanan yang terencana dilakukan oleh tahanan politik, seperti mencuri hasil kebun militer, merusak kebunkebun militer, membunuh ternak militer dan lain sebagainya.

Bertahan di tengah perbudakan militer melalui kerja paksa dan kontrol direspon oleh tahanan politik dengan beragam strategi. Kemudian pada titik balik tertentu, tampaknya bahwa keberadaan kamp pengasingan Moncongloe telah memperkuat solidaritas antara tahanan politik satu dengan yang lain yang diekspresikan melalui politik resisten sehari-hari. Politik resisten sehari-hari pada dasarnya dilakukan dalam rangka memperjuangkan atau mendapatkan sumber-sumber yang langka (makanan, hiburan pengobatan dan lain sebagainya) serta keamanan diri. Pola resistensi kadang-kadang individual dan kadang-kadang berkelompok sesuai dengan target yang ingin dicapai, tetapi akhir tahun 1969 terdapat resistensi massal ketika bahan-bahan kebutuhan pokok semakin kurang, kontrol militer semakin kuat, sementara solidaridas tahanan politik juga semakin menguat dan diekspresikan dalam politik resistensi kolektif yang kuat pula.

\section{UCAPAN TERIMA KASIH}

Terima kasih diucapkan kepada Tim Redaksi Al Qalam yang telah memuat artikel hasil penelitian tentang Sejarah Alternatif Tanah Merah. Upaya tim redaksi menyeleksi, mengedit, dan memuat makalah ini merupakan kerja pengabdian yang luhur pada peningkatan ilmu pengetahuan dan peningkatan demokratisasi. Hal serupa diucapkan kepada para informan, pemerintah Sulawesi Selatan, Kabupaten Gowa dan masyarakat Moncongloe atas sumbangsinya dalam penggalian data dan fakta berkaitan dengan alternatif sejarah Moncongloe. Semoga hasil penelitian ini dapat memperkaya keilmuan dan dapat dijadikan bahan dalam menata kehidupan bermasyarakat, khususnya oleh masyarakat Moncongloe.

\section{DAFTAR PUSTAKA}

\section{Arsip}

Arsip Muhammad Saleh Lahade Petunjuk PANGKOPKAMTIB No. PELAK-002/ KOPKAMTIB/10/68 tentang Kebijaksaanaan Penyelesaian Tahanan/Tawanan G 30 S/PKI

Tj. Kadullah, Jalan tak berujung (1) Arsip pribadi.

\section{Buku, Artikel}

Ahmad, Taufik. 2009. Kamp Pengasingan Moncongloe, Jakarta: Desantara.

2012. South Sulawesi: The Militery,

Prison Camps and Forced Labour dalam Douglas Kammed dan Katharine Mc Gregor (ed) The Contours of Mass Violence in Indonesia, 1965-68. Singapore: NUS Press. , 2013, Bandit dan Pejuang: Sejarah Sosial Politik Polongbangkeng 19305 - 1960, Laporan Penelitian, Balai Pelestarian Nilai Budaya Makassar

Dg. Patunru, Abd. Razak. 1982. Sejarah Gowa. Ujung Pandang: Yayasan Kebudayaan Sulawesi Selatan.

Cribb, Robert (ed). 1990. The Indonesian Killings 1965-1966: Studies from Java and Bali. Clayton: Monash University Centre of South East Asia Studies.

Krisnadi. 2001. Tahanan Politik Pulau Buru (19691979). Jakarta: LP3S.

Mattulada. 1982. Menyusuri jejak Makassar dalam Sejarah. Jakarta: Bhakti Baru.

Nordholt, Henk Schulte, dkk (ed) 2008. Perspepetif Baru Penulisan Serjarah Indonesia, Jakarta: Yayasan Obor Indonesia

Scott, James. 1998. Seing Like a State: How Certain Schemes to Improve the Human Condition Have Failed. New Haven/London: Yale University Press.

Setiawan, Hesri. 2004. Memoar Pulau Buru. Magelang: IndonesiaTera.

Sulistiyo, Hermawan. 2001. Palu Arit di Ladang Tebu : Sejarah Pembantaian Massal yang Terlupakan (Jombang-Kediri 1965-1966). Jakarta: Kepustakaan Populer Gramedia.

Toer, Pramoedya Ananta. 1995. Nyanyi Sunyi Seorang Bisu. Jakarta: Lentera. 